\title{
Reference Skills or Human-Centered Design: Towards a New Lexicographical Culture
}

Sven Tarp, Department of Afrikaans and Dutch, Stellenbosch University, South Africa; Centre for Lexicographical Studies, Guangdong University of Foreign Studies, China; International Centre for Lexicography, Universidad de Valladolid, Spain; and Centre for Lexicography,

University of Aarhus, Denmark (st@cc.au.dk) and

Rufus Gouws, Department of Afrikaans and Dutch, Stellenbosch University, South Africa (rhg@sun.ac.za)

\begin{abstract}
This paper deals with the design of digital lexicographical products. It introduces the philosophy of human-centered design, as explained in the work of Don Norman, and discusses central design concepts like affordances, signifiers, feedback, and other forms of good communication from lexicographer to user. The successful use of traditional dictionaries often relied on the presumed reference skills of the envisaged target user group. Especially in printed dictionaries with their space restrictions, lexicographers used condensed entries, abbreviations, and different types of structural indicators to save space. This often was to the detriment of the user who struggled to retrieve the required information from the data on offer. The digital environment has created new opportunities for lexicographers to assist their users in a far better way. Using principles of human-centered design, this paper shows the emergence of the application of some of these approaches in existing online dictionaries. Going beyond the scope of traditional online dictionaries, examples are taken from integrated e-reading dictionaries and lexicography-assisted writing assistants where even stronger user-centered design features come to the fore with regard to respectively text reception and text production assistance. Where the original concept of a dictionary culture was primarily based on the reference skills of the user, a new lexicographical culture is suggested that adheres to human-centered design principles. It places the responsibility on the shoulders of the lexicographer to design lexicographic products that enable intuitive use and ensure improved lexicographic success.
\end{abstract}

Keywords: REFERENCE SKILLS, DICTIONARY CULTURE, LEXICOGRAPHERS' RESPONSIBILITY, HUMAN-CENTERED DESIGN, INTUITIVE USE, AFFORDANCES, SIGNIFIERS, FEEDBACK, INTERDISCIPLINARY COLLABORATION, NEW LEXICOGRAPHICAL CULTURE

Opsomming: Naslaanvaardighede of mensgerigte ontwerp: Op pad na 'n nuwe leksikografiese kultuur. Hierdie artikel handel oor die ontwerp van digitale leksikografiese produkte. Dit stel die filosofie van mensgerigte ontwerp bekend, soos uiteengesit in die 
werk van Don Norman, en bespreek sentrale ontwerpsbegrippe soos beskikbaarhede, aanduiders, terugvoering en ander vorme van goeie kommunikasie tussen leksikograaf en gebruiker. Die suksesvolle gebruik van tradisionele woordeboeke het dikwels berus op die vermeende naslaanvaardighede van die veronderstelde teikengebruikersgroep. Veral in gedrukte woordeboeke met hulle ruimtebeperkings het leksikograwe verdigte inskrywings, afkortings en verskillende tipes struktuurmerkers gebruik om ruimte te spaar. Dit was dikwels tot die nadeel van die gebruiker wat moes sukkel om die nodige inligting aan die aangebode data te onttrek. Die aanlyn omgewing het nuwe moontlikhede vir leksikograwe geskep om hulle gebruikers op ' $n$ baie beter manier by te staan. Met behulp van beginsels van mensgerigte ontwerp, soos uiteengesit in die werk van Don Norman, bespreek hierdie artikel die inwerkingstelling van die toepassing van sommige van hierdie benaderings in bestaande aanlyn woordeboeke. Deur verder as tradisionele aanlyn woordeoeke te kyk, word voorbeelde uit geïntegreerde e-leeswoordeboeke en leksikografies ondersteunde skryfhulpe geneem waar nog sterker mensgerigte ontwerpskenmerke m.b.t onderskeidelik teksresepsie- en teksproduksiehulp na vore tree. Waar die oorspronklike begrip van 'n woordeboekkultuur primêr berus het op die naslaanvaardighede van die gebruiker word 'n nuwe leksikografiese kultuur voorgestel wat op mensgerigte ontwerpsbeginsels steun. Dit plaas die verantwoordelikheid op die skouers van die leksikograaf om leksikografiese produkte te ontwerp wat intuïtiewe gebruik moontlik maak en verbeterde leksikografiese sukses verseker.

Sleutelwoorde: NASLAANVAARDIGHEDE, WOORDEBOEKKULTUUR, LEKSIKOGRAWE SE VERANTWOORDELIKHEID, MENSGERIGTE ONTWERP, INTUÏTIEWE GEBRUIK, BESKIKBAARHEDE, AANDUIDERS, TERUGVOERING, INTERDISSIPLINÊRE SAMEWERKING, NUWE LEKSIKOGRAFIESE KULTUUR

Great designers produce pleasurable experiences.

Norman (2013: 10)

\section{Introduction}

Wiegand (1998) rightly defined dictionaries as utility tools produced with the genuine purpose of satisfying human needs, or more precisely, information needs of specific types. This fundamental approach to the discipline, which can be considered the cornerstone of his theoretical building, is shared by many other lexicographers although frequently disagreeing with Wiegand in other aspects, among them Bergenholtz and Tarp (2003).

During most of their existence, the possession and usage of dictionaries have been the privilege of the few due to social and technological constraints. For centuries, the artisanal compilation methods and the material used to produce dictionaries strongly limited the number of available copies and made them inaccessible and unaffordable for most people who, in addition, could frequently not even read and write. All this changed with the introduction and improvement of the printing technology and the general alphabetization required by the industrial revolution. Especially from the late nineteenth century on- 
wards, the editions grew bigger and bigger allowing dictionaries to reach out to the majority of people. Like other classes of utility tools, dictionaries became increasingly everyday things, at least in the most developed countries.

Being products ideally conceived to meet human needs, dictionaries and other lexicographical tools would be expected to be human-centered in all aspects, including their design. However, technological progress, although laying the foundation for lexicographical products of still higher quality, has not been unequivocally favourable to lexicography. Hanks (2013: 512), for instance, reports how the new printing technology and typographic achievements enabled "lexicographers to cram vast quantities of information elegantly and legibly onto each page and to disseminate large numbers of identical copies of completed dictionaries quickly and efficiently". The downside of this positive development is that the large amount of "information" (read: data) gave rise to more and more complex dictionary articles and structures.

Wiegand (1990) and Wiegand et al. (2013) have detected and described numerous lexicographical structures representing different types of relationship between the various classes of data contained in dictionaries. Practical lexicographers often negotiate only a few structures (like macro- and microstructures) and take little cognizance of the many and diverse structures prevailing in their dictionaries. But these structures exist objectively. Together with data condensation, they are probably a major reason why dictionary successful consultation often still turns out to be difficult for many users. To this should be added the still bigger editions that also contributed to a growing distance between lexicographers and users. Whereas lexicographers in the small-edition era usually had personal knowledge of a relevant segment of their target group, this segment grew smaller and less significant over time. The inevitable result was lexicographical alienation with the dictionary user ending up as a "well-known unknown" (Wiegand 1977).

The alienation, combined with a lack of personal feedback, impeded a comprehensive insight into the problems experienced by dictionary users. It may also have created a sort of academic arrogance among some lexicographers who shifted the responsibility from themselves to their users. The latter's inadequate "reference skills" were blamed for the consultation problems. The need for a special "dictionary culture" with school children and other potential users being trained in look-up techniques was promoted (see Yamada 2014, among many others). This situation may look comfortable from the lexicographer's point of view. But it strongly contradicts the very nature of dictionaries and other lexicographical products as utility products that are not only designed to meet human information needs but also expected to allow easy, fast, and successful consultation. That is, it contradicts the principle of humancentered design.

These imperfections may, to a certain extent, have been justified in the era of printed dictionaries where the technical room for manoeuvring was tight. But this is no longer the case in the present era where disruptive technologies 
make allowance for completely new ways of consulting lexicographical products. We therefore strongly advocate that the responsibility for a good consultation experience should shift from the user to the producer. With this purpose, we will introduce the modern concept of human-centered design as developed by Norman (2013). In the subsequent sections, we will try to apply this concept to "traditional" dictionaries as well as other lexicographical products integrated into digital devices like e-readers and writing assistants. Based on the positive aspects from this discussion, we will finally outline a new lexicographical culture under the current technological possibilities.

\section{Concept of human-centered design}

There may be few lexicographers who know the term Norman doors. But among industrial designers of everyday things, the term is well-known. It refers to doors whose design makes it difficult, or even impossible, to see how they open and should be used. The doors are named after the American engineer and cognitive scientist Don Norman who has severely criticized their userunfriendly design and used them to illustrate the need for a human-centered approach.

Norman has authored several books on industrial design, among them Emotional Design: Why We Love (or Hate) Everyday Things (Norman 2004), Living with Complexity (Norman 2010), and The Design of Everyday Things (Norman 2013). He was one of the experts that were called upon to analyze the nuclear accident at Three Mile Island back in 1979. Here, the committee he was on discovered that "the plant's control rooms were so poorly designed that error was inevitable: design was at fault, not the operators" who initially were blamed for the accident (Norman 2013: 7).

This conclusion goes like a red thread through his writings. Far too often users are blamed when they make mistakes or do not know how to use modern products. This holds true both for simple everyday objects where difficulties may lead to frustration, and for complex technological products where the consequences may be much more severe.

It is time, Norman tells us, to "reverse the situation". It is the duty of designers "to understand people", and not the other way around. A major problem is that design to a large extent is done by "engineers who are experts in technology but limited in their understanding of people". These experts mistakenly think "that logical explanation is sufficient", and that everything would work smoothly if "only people would read the instructions". However, "humans are amazingly complex". We therefore have to "accept human behavior the way it is, not the way we would wish it to be" (p. 6).

As a solution, Norman suggests human-centered design (HCD) which he defines as "an approach that puts human needs, capabilities, and behavior first", and "then designs to accommodate those needs, capabilities, and ways of behaving" (p. 8). The overall objective is to create products that are not only 
"understandable and usable". In the best of cases, they should also be "delightful and enjoyable" which means that "attention must be paid to the entire experience", i.e. "the aesthetics of form and the quality of interaction" (p. 4). This focus on aesthetics is due to research on emotion and cognition showing that "attractive things really do work better" (Norman 2004: 17).

The human-centered approach regards the best design to be invisible in the sense that it does not draw attention to itself and allows its users to intuitively know both the purpose and the functioning of the product. Besides a solid understanding of both technology and human psychology, this kind of design requires "good communication" where the device indicates to its user "what actions are possible, what is happening, and what is about to happen" (Norman 2013: 8). In this respect, good communication is especially important when there are problems:

This is where good design is essential. Designers need to focus their attention on the cases where things go wrong, not just on when things work as planned. Actually, this is where the most satisfaction can arise: when something goes wrong but the machine highlights the problems, then the person understands the issue, takes the proper actions, and the problem is solved. When this happens smoothly, the collaboration of person and device feels wonderful.

(Norman 2013: 9)

As can be seen, the human-centered design philosophy is exciting. Its relevance to modern dictionaries and other lexicographical products is evident. But how can this philosophy actually be applied? In his book, Norman (2013) discusses a number of concepts, or principles, and illustrates them with a large number of practical examples. An in-depth discussion of all these interesting issues goes beyond the scope of this article. We have therefore selected a few questions that we consider particularly relevant to lexicography.

Norman initially draws our attention to two important characteristics of good design, namely discoverability and understanding:

Discoverability: Is it possible to even figure out what actions are possible and where and how to perform them? Understanding: What does it all mean? How is the product supposed to be used? What do all the different controls and settings mean? (Norman 2013: 3)

The answers to these questions are usually given in manuals or through personal instruction. Norman, by contrast, insists that manuals and instructions are only required, if "the device is indeed complex, but it should be unnecessary for simple things" (p. 3). This is certainly a discussion relevant to lexicography: Do we need user guides? Are our products simple or complex? The discussion of user guides has been going on for years and no final agreement has been reached, cf. Kirkpatrick (1989). Nielsen (2005), Vrbinc and Vrbinc (2020). Hopefully, the discussion can now be placed on more solid ground. 
According to Norman (2013), discoverability results from the designers' appropriate application of six fundamental psychological concepts: affordance, signifiers, feedback, constraints, mapping, and conceptual model. We will briefly discuss the first three concepts which seem to be most relevant to the purpose of this article.

An affordance is not a property in itself, but a relationship between the properties of both a physical object and a person that is interacting with this object. An affordance helps the person figure out how the object can be used and "what actions are possible without the need for labels or instructions" (p. 13). For instance, "a chair affords ('is for') support and, therefore, affords sitting" (p. 11). Affordances may be visible or not. But to be effective, they should be perceivable and discoverable. If this is not the case, "some means of signaling its presence is required" (p. 12). This is the role of the signifier.

A signifier is "any perceivable indicator that communicates appropriate behavior to a person" (p. 14). An example could be the sign PULL on a door. Norman considers signifiers to be more important than affordances, because "they communicate how to use the design." (p. 19). As to the mutual relationship between the two concepts, he writes:

Some affordances are perceivable. Others are invisible. Signifiers are signals. Some signifiers are signs, labels, and drawings placed in the world, or arrows and diagrams indicating what is to be acted upon and in which direction to gesture, or other instructions. Some signifiers are simply the perceived affordance, such as the handle of a door or the physical structure of a switch. (Norman 2013: 18)

Feedback is a well-known concept in information science. Norman views it as an important form of communication that must be given after any action in order to confirm the action and communicate its results. Feedback must be immediate and informative. Norman (2013) holds that poor feedback can be worse than no feedback at all, because "it is distracting, uninformative, and in many cases irritating and anxiety-provoking" (p. 24). But the solution is not to resort to information overload as "too much feedback can be even more annoying than too little" (p. 24). From this perspective, feedback must be planned and prioritized. Unimportant information must be presented in an "unobtrusive fashion", whereas important signals should be "presented in a way that does capture attention" (p. 25).

Norman (2013) stresses several times that the human-centered design process starts with a good understanding of people and their needs, i.e. "the needs that the design is intended to meet" (p. 9). How should this understanding be obtained? Norman recommends that it is done primarily through observation. His argument in favor of this method is that "people themselves are often unaware of their true needs, even unaware of the difficulties they are encountering" (p. 9). To design based on the results from observation, he advocates the use of iterative processes with test-driven development: 
[...] the HCD principle is to avoid specifying the problem as long as possible but instead to iterate upon repeated approximations. This is done through rapid tests of ideas, and after each test modifying the approach and the problem definition. The results can be products that truly meet the needs of people. (Norman 2013: 9)

The design of modern technological products requires interdisciplinary collaboration. Such collaboration, however, is far from trouble-free. Experts from different fields tend to have different goals and principles and consider their specific contribution to the final product the most important:

One discipline argues that it must be usable and understandable, another that it must be attractive, yet another that it has to be affordable. Moreover, the device has to be reliable, be able to be manufactured and serviced. It must be distinguishable from competing products and superior in critical dimensions such as price, reliability, appearance, and the functions it provides. Finally, people have to actually purchase it. It doesn't matter how good a product is if, in the end, nobody uses it. (Norman 2013: 35)

Norman believes that "everybody is right", and that the successful product has to meet all these requirements. This requires a strong sense of business, great management skills, and the ability to coordinate the many, separate disciplines. The different experts must be convinced to "understand the viewpoint" of the other experts and "to think of the design from the viewpoint of the person who buys the product and those who use it, often different people" (p. 35).

\section{Design of dictionaries in the digital era}

Dictionaries are utility tools. For many people, they have become everyday things. The principles of human-centered design are therefore relevant and applicable also to this group of objects. It is no secret that dictionaries vary considerably in terms of quality, and it is not difficult to find Norman dictionaries. Many printed dictionaries, for instance, are not sufficiently focused on the particular user needs they intend to meet. Instead, they apply a sort of scattergun technique based on the old paradigmatic idea that the compilation of a dictionary is only realistic if "it takes into account the likely needs of various users in various situations" (Hartmann 1989: 104). In addition, space constraints frequently compel lexicographers to negotiate quality in some aspects at the expense of shortcomings in other aspects (see, e.g., Rundell 2015a). Labels like Norman dictionaries are uncalled for in this context.

The digital technology changes the rules. It opens completely new horizons and poses new challenges as well. The capacity to store lexicographical data is now unlimited whereas the presentation of these data is subject to new types of constraints. The temptation of resorting to data overload, for instance, should be resisted (see Gouws and Tarp 2017). Lexicographers have to adapt to the new reality. They must develop observational skills to detect not only the 
foreseen users' information needs but also their "capabilities and ways of behaving" in the digital environment. The determination and inclusion of lexicographical data to satisfy the mentioned needs are paramount. Yet, it is clearly not enough. Users should also be able to consult the dictionary intuitively, i.e. to find these data and retrieve the needed information as fast and easy as possible and without any instructions. Moreover, the entire consultation experience should be "delightful and enjoyable" in terms of aesthetics and interaction between user and device. To provide such an experience, interdisciplinary collaboration becomes a necessity as Norman rightly states.

In the following, we will briefly look at various online dictionaries. Our aim is not to analyze these dictionaries in all details or describe the current state-of-the-art but to highlight some positive aspects as well as challenges still to be solved. Today, users typically access online dictionaries using bookmarks, apps, or searches on the Internet. Basically, it is quite similar to the old days when they took the printed dictionaries down from the shelves or went to the library to get them. In both cases, the users are aware that they have a reference tool in front of them. In this respect, dictionaries do not need to call attention to themselves. But they do need to make their affordances visible to the users.

In "traditional" online dictionaries, the consultation process starts in the search bar, i.e. the box that affords the search. Netizens and other navigators on the Internet are familiar with search bars and do not need additional signifiers. Nonetheless, many dictionaries add such signifiers, for instance, the Oxford Dictionary on Lexico (see Figure 1). The text Type word or phrase is presented in subdued color. As such, it is unobtrusive and less annoying for frequent users.

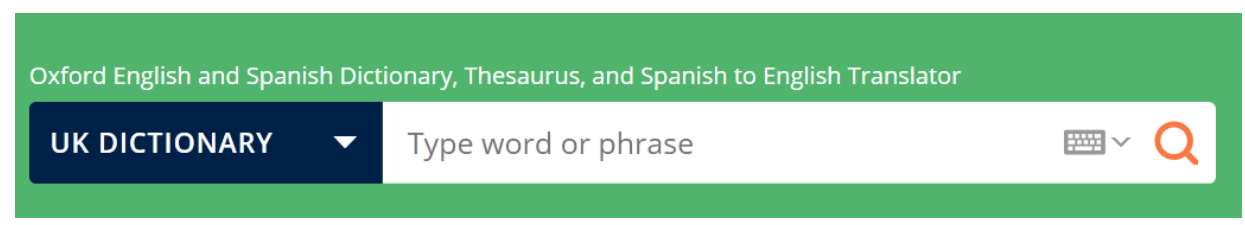

Figure 1: Search bar in Oxford Dictionary on Lexico

The down-pointing arrow in the dark field to the left allows the user to choose between six mono and bilingual dictionaries with English and Spanish as well as two grammars of the respective languages. In the upper right corner of the default page (not shown in Figure 1), users also have the option to change the site language from English to Spanish. Other dictionaries have similar functionalities. Cambridge Dictionary, for instance, allows its users to choose between 16 different site languages and 26 dictionaries plus one grammar, in the last case by clicking on the signifier ":" (see Figure 2). 


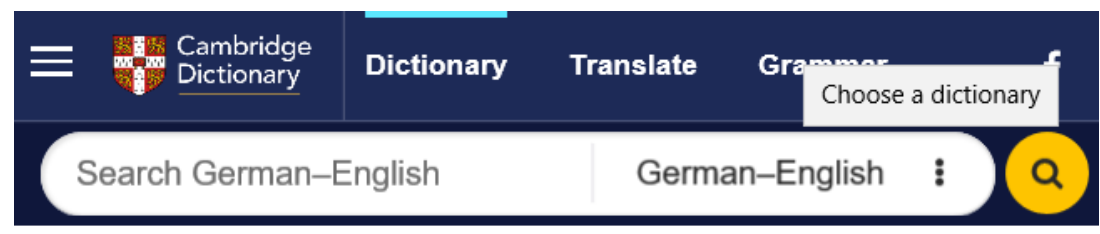

Figure 2: Search bar with the option to choose dictionary in Cambridge Dictionary

The search bar in Lexico has other affordances that users can discover by means of signifiers. A click on the keyboard icon visualizes a keyboard with special letters whereas a click on the magnifying glass initiates the search process. Once the user starts typing, the signifier Type word or phrase disappears and the typed letters appear in normal black color (see Figure 3). Besides, a box with lemmatized word terminations immediately visualizes together with a new button (X). The former allows the users to access one of the suggested words with a simple click whereas the latter allows them to reset the search query and start from scratch. These affordances and signifiers have become conventional and are used in many online dictionaries and search engines like Google. When applied correctly, they undoubtedly guarantee a pleasurable beginning of the consultation process.

\begin{tabular}{|l|}
\hline cowar \\
\hline coward \\
cowardice \\
cowardliness \\
cowardly \\
cowardly custard \\
Coward, Sir Noël \\
cowardy \\
\hline
\end{tabular}

Figure 3: Search bar in Lexico with lemmatized word terminations and reset button

As Norman stated, good communication is important, especially when something goes wrong. Two main problems may occur: lemma lacunae or misspelling of the search query. In both cases, the users need a response. Let us take the archaic adjective specifical as an example. In various dictionaries like Lexico, Cambridge, Longman, and Macmillan, the users are informed that the search for specifical did not yield any result. Instead, several alternative spelling 
candidates are suggested, among them the modern variant specific as can be seen in Figure 4.

\title{
Sorry, no search result for specifical.
}

\author{
DID YOU MEAN: \\ specifically \\ specific \\ specifics \\ specificity \\ special \\ specified \\ specifies \\ specification \\ specifications \\ apolitical
}

Figure 4: Response to the query "specifical" in Macmillan

This kind of feedback is not bad, but neither is it perfect. The underlying problem is the design and the challenges it poses to the users. The correct spelling variant has to be identified and clicked on in order to access the article specific. This takes some time and may create anxiety among some users. It would probably be the only possible solution if it were a case of misspelling. But here it clearly is a question of a lemma lacuna even though specifical is old fashioned. As can be seen in Figure 5, Merriam-Webster has opted for a different method. In this dictionary, specifical has its own article where the users are informed that the word is archaic (= should not be used) and means specific. Even so, if they do not know the meaning of specific or how to use it, they will have to click on the word to access the corresponding article. In both cases, a more humancentered solution with improved communication would have saved the extra click and prevented the possible anxiety.

\author{
specifical adjective \\ Q Save Word \\ spe-cifi.cal | \-fäkəl | \\ Definition of specifical \\ archaic \\ :SPECIFIC
}

Figure 5: The article "specifical" in Merriam-Webster 
The next phase in a successful consultation process is the display of a dictionary article. Figure 6 shows such an article from the Diccionario de la lengua española edited by the Royal Spanish Academy. Although this dictionary has a number of relevant affordances and signifiers to assist the search process, the resulting article is disappointing. Like the monarchy, it seems like something from the past. The compact definitions and metatexts are clearly influenced by traditional conventions and space restrictions in printed dictionaries. Even for native speakers, it is difficult to grasp the meaning of the different senses. Grammatical abbreviations like U. t. c. intr. and prnl.p. us. are simply hogwash for most users. This Norman article represents a general problem and is typical for many online dictionaries that are based on lexicographical databases designed for the printed book format. The challenge is not to redress these dictionaries in digital bobbin laces but to rethink the whole concept from scratch starting with the databases. Apart from user needs and behavior, the design has to accommodate the foreseen user group's capabilities which seem to have been completely ignored in this case.

\section{consentir Conjugar}

\section{Del lat. consentire.}

Conjug. c. sentir.

1. tr. Permitir algo o condescender en que se haga. U. t. c. intr.

2. tr. Mimar a los hijos, ser muy indulgente con los niños o con los inferiores.

3. tr. creer (\|l tener algo por cierto).

4. tr. Der. Otorgar, obligarse.

5. tr. Der. Arg. Acatar una resolución judicial o administrativa sin interponer contra ella los recursos disponibles.

6. tr. p. us. Dicho de una cosa: Soportar, tolerar algo, resistirlo.

7. prnl. p. us. Dicho de una cosa: Resentirse, desencajarse, principiar a romperse. El buque se consintió.

Figure 6: Article from the Dictionary of the Royal Spanish Academy

Cambridge and Oxford are among the publishers of dictionaries that have advanced most towards a human-centered digital design. Figure 7 shows a screenshot of the article consent in Oxford's Lexico. 


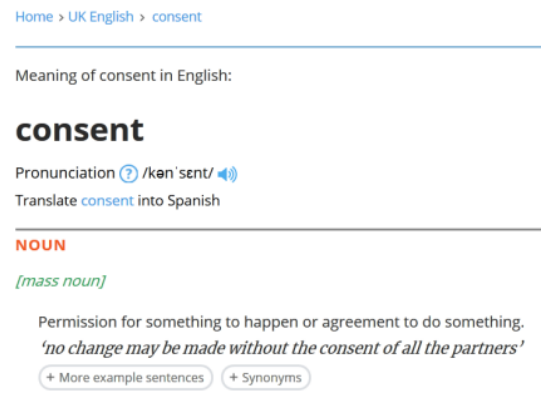

Figure 7: Extract of article from Lexico

The full article treats both noun and verb, two so-called phrases, as well as etymology. It also includes a large amount of hidden text (examples sentences and synonyms). Especially the former are very voluminous. If these data categories were displayed as default, it would be necessary to scroll down several pages to get an overview of the complete article. This would probably challenge many users and, in some cases, lead to anxiety and abortive consultation. From this perspective, the design is aesthetic and user-friendly. This also holds true for the two types of signifiers (+ More example sentences and + Synonyms). It is easy for the users to see how the hidden text can be visualized, and it is also easy to see how it can be hidden again. As can be seen in Figure 8, the signifier is now placed on a dark background color, and plus (+) has changed to minus (-). There is little room for misunderstandings.

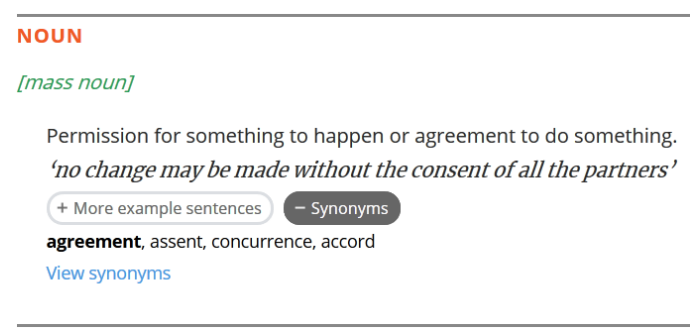

Figure 8: Extract of article from Lexico with synonyms expanded

Synonyms are particularly useful in connection with text production. A major problem is here to find their exact meaning and choose the most appropriate candidate to be used in a given context. Users may, therefore, be tempted to click on View synonyms to get more information on meaning and usage. The disappointment will be big. They are referred directly to a classic thesaurus with more synonyms (and antonyms) but no definitions (see Figure 9). It is a blind alley. If they want definitions of the listed synonyms, they will have to start a new consultation and look them up one by one, a very time-consuming 
operation that takes focus away from the writing process. The good news, however, is that they can opt to return to the previous page (Figure 8) by simply clicking on consent in See definition of consent. The possibility to close an expanded text or return to a previous page is another fundamental characteristic of good human-centered design.

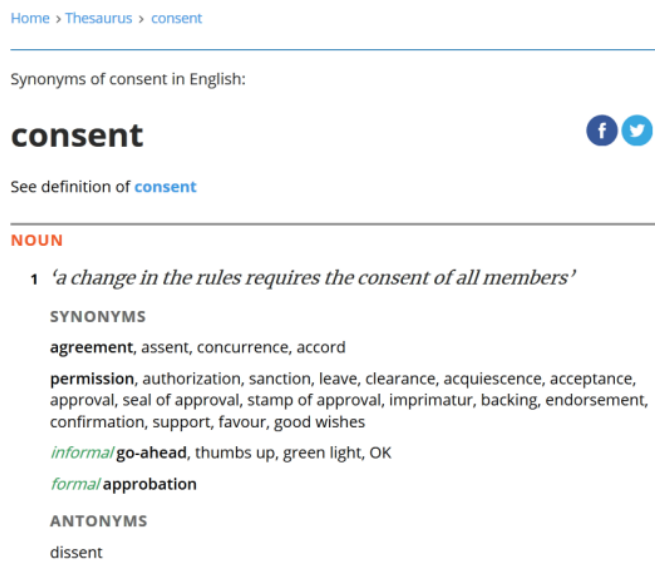

Figure 9: Extract of article from Lexico with synonyms

Cambridge, which has a design very similar to Lexico, misses this last option. When its users click on See more results in the thesaurus, they are directed to a page where there are no perceivable affordances that allow them to return to the previous page. By contrast, each of the synonyms and related words listed on this page affords an additional click that provides access to a definition, a very useful piece of information as mentioned above. The dark side of the coin, however, is that the users who follow this path once more end up in a remote area with no return ticket. Not even the best reference skills can bring them back. It is the design that fails. The database contains the required data but they are not presented and connected in a user-friendly way. If users want to know the meaning of various synonyms to pick up the most suitable one, the only option is to start from scratch and conduct a series of new consultations. The entire experience is anything but "delightful and enjoyable". In this respect, a marriage between Cambridge and Oxford, a lexicographical Oxbridge, would be an important step forward towards a more human-centered design of online dictionaries.

In the previous paragraphs, we have seen a few examples of how the most prestigious dictionaries are adapting to the online environment and introducing interesting solutions. But there are also serious challenges to be solved before they can claim to fully comply with the principles of human-centered design. The challenges seem to have two main sources: a hangover from the print era and problems with the business model. 
Many databases sustaining online dictionaries still have their origin in the print era, where the "exclusion criteria" dominated due to space restrictions (Rundell 2015a: 312). The problem is not only ultra-short definitions and obscure abbreviations like the ones we saw in the dictionary from the Spanish Academy. Equally serious are all the possible lemmata, senses, and remaining data that have been discarded by the exclusion criteria. It takes time to remedy these lacunae. It entails a mental awakening and frequently also the design of completely new lexicographical databases. As long as the "various users in various situations" cannot find the lexicographical data they need in these situations, online dictionaries cannot be classified as fully human-centered.

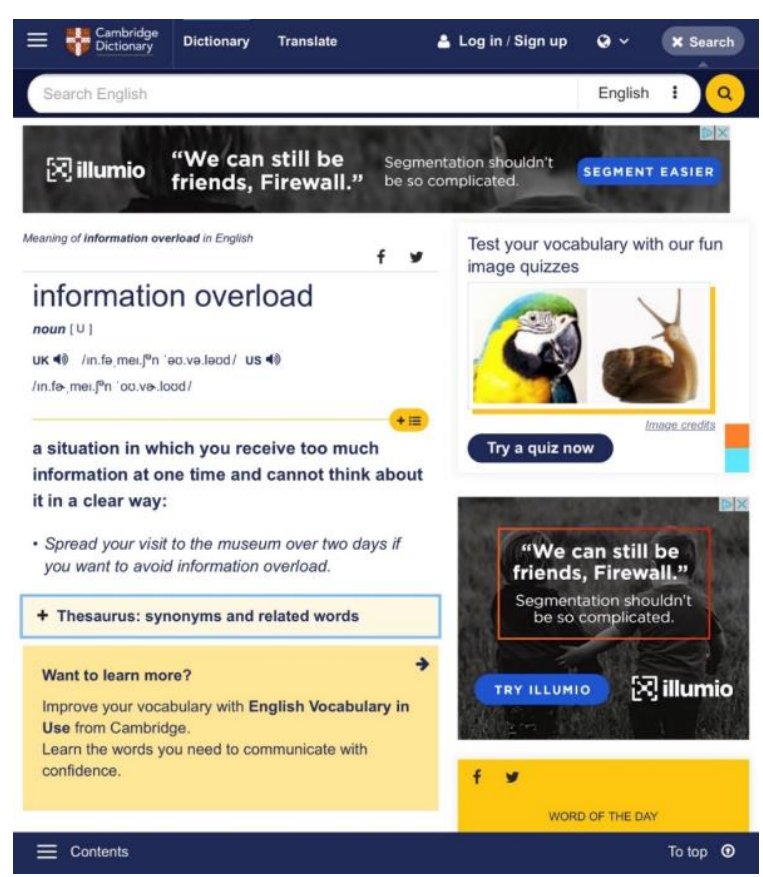

Figure 10: Dictionary article with advertisements from Cambridge Dictionary

The other problem is the business model. Due to financial constraints, all the online dictionaries consulted above, at least in their free-access editions, have "decorated" the pages with click-through banners and advertisements for themselves or other companies. An example is the screenshot from Cambridge Dictionary shown in Figure 10. The decoration may guarantee some revenue, but it may also divert the users' attention and give them a far from pleasurable experience. The Royal Spanish Academy has even honored its dictionary sponsor, one of the country's biggest banks, in the very search bar (see Figure 11). The obtrusive font sizes and colors are like vinegar in the morning coffee, a bad way to start the day. 


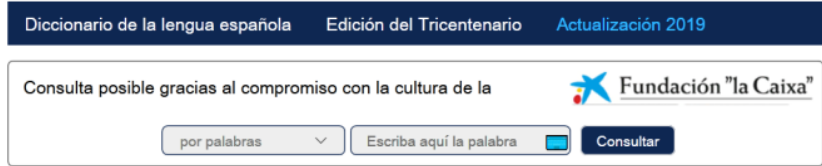

Figure 11: Search bar in the Dictionary of the Royal Spanish Academy

A pleasurable and aesthetic dictionary experience requires, as a minimum, that all unnecessary "noise" is removed allowing users to exclusively focus on the lexicographically relevant items. One of the few providers of online dictionaries who have understood this is Ordbogen.com. Figure 12 shows the article consent from its monolingual English dictionary that has been licensed from Random House. If we abstract from the content and structure of the displayed article, we can see an uncomplicated design characterized by simplicity. The article is the central issue. In addition, we find the company logo, site languages, login icon, search bar, license reference, access button to all dictionaries, feedback icon (bulb), and language and technical support icon (speech bubbles). All of this presented in a balanced and unobtrusive way with the dictionary article as the main attraction. This is everything needed to make full use of this page. Only the content of the dictionary article calls for improvement in various aspects but the roots of this last problem have already been uncovered above.

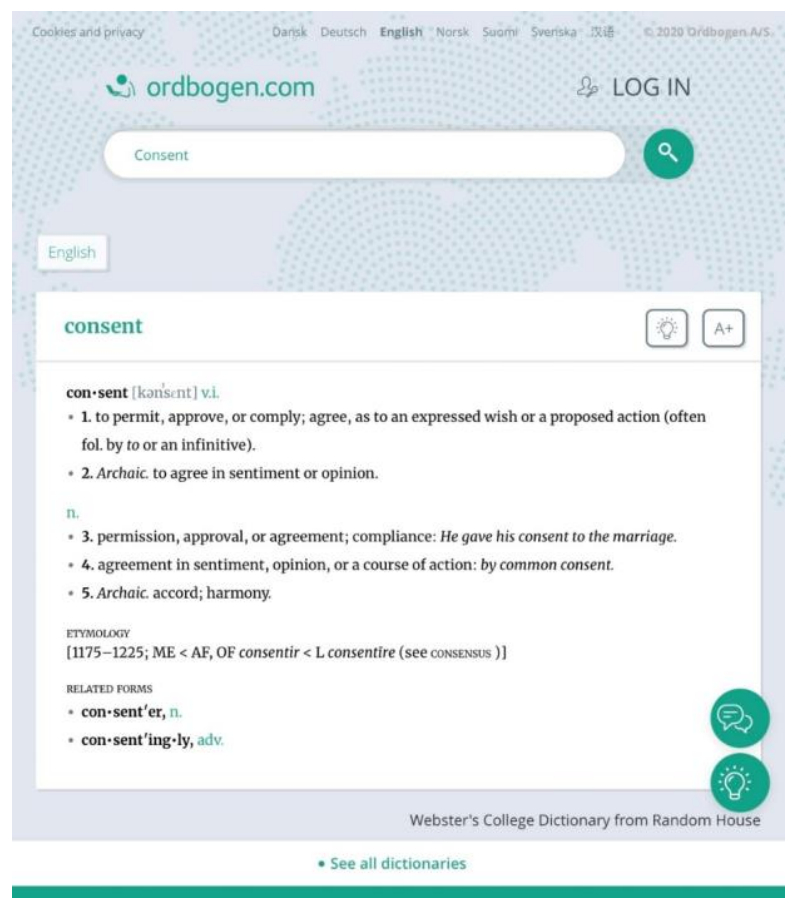

Figure 12: Design of page with dictionary article in Ordbogen.com 


\section{Design of integrated e-reading dictionaries}

By integrated e-reading dictionaries, we understand any dictionary that provides direct and immediate assistance to text reception in digital devices like ereaders, tablets, smartphones, and laptops. The benefit of such dictionaries is that readers can access them by simply touching or clicking on a word in the text they are reading. This saves time and is less disturbing for the reader who may be very focused on the content of the text. In the following, we will use the iPad to discuss some features and requirements for the design.

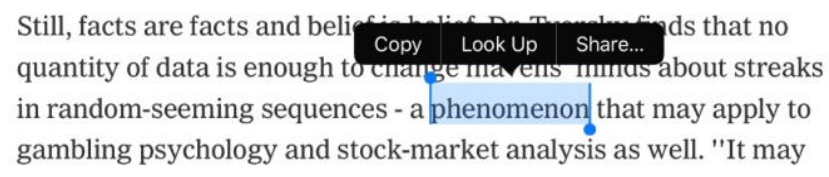

Figure 13: Touching a word on the screen

Figure 13 shows what happens when the reader touches a word in an article from the New York Times uploaded on an iPad. A small box with three options immediately pops up, one of them inviting the user to start a lexicographical consultation. In the figure, we see two lexicographically relevant affordances: The first is the individual words in the text that afford a touch in order to access the box, and the second is the central section of the box that also affords a touch, in this case to start the real consultation process. However, only this second affordance is perceivable. If the user does not know that a touch on the screen can provide access to further data, nothing will happen. In fact, one of the authors of this article had used his iPad several years before he discovered this functionality. The information can be found in the extensive user manual that can be consulted online, but how many users read such manuals? The designers should, therefore, have added a signifier making the affordance discoverable, for instance: "Touch a word to get a definition". Of course, it can be annoying for the users to see this message repeated every time they read a text in one of the applications that allow this functionality. A solution could therefore be to add "Don't show this message again", a standard text already used in similar cases.

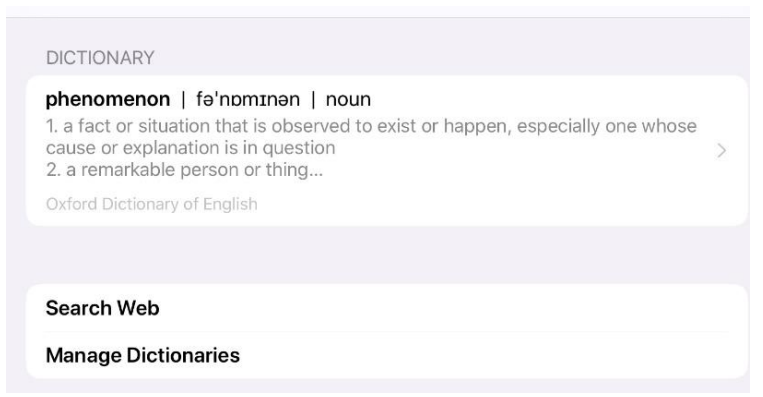

Figure 14: Dictionary overview: phenomenon 
A click on "Look Up" will take the readers to a page with three options (see Figure 14). First, there is a link to a directory where the users can activate and deactivate the available dictionaries at their choice. Second, there is the possibility to search for more information about phenomenon on the Internet. And third, there is a list with extracts from the dictionaries that are activated and can be accessed (in this case only one dictionary has been selected). The use of perceivable affordances and signifiers makes it easy to figure out which actions can be performed. The access route is laid bare. Noticeable are the subdued colour of the dictionary extract and the two conventional signifiers attached to it: The sign "..." at the end of the extract is used to indicate that more text follows, whereas the small right-pointing arrow in the right margin signals how to access this text (by clicking or touching). This is an important piece of communication that allows the readers to continue the consultation.

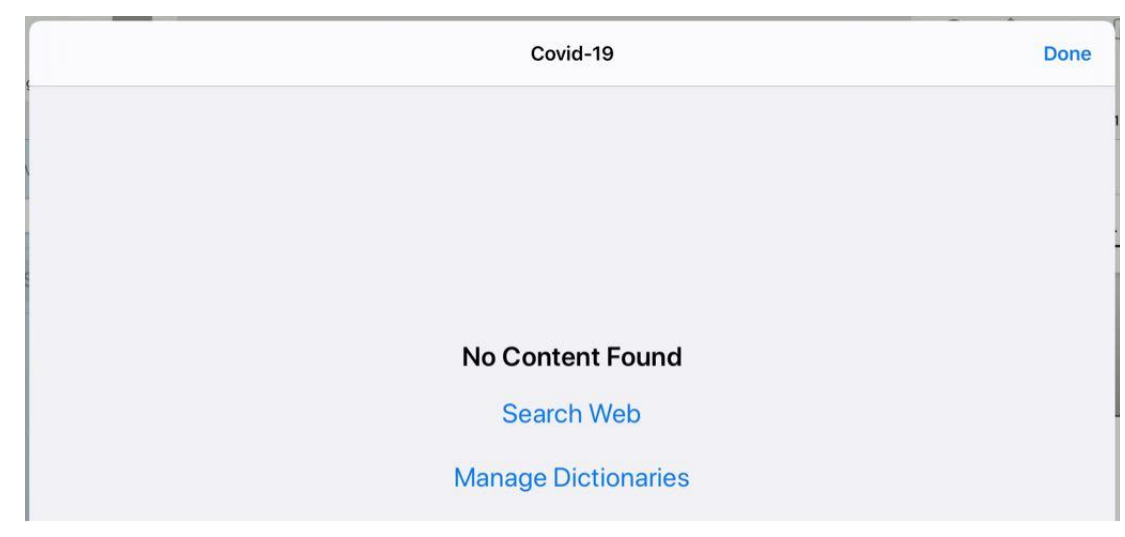

Figure 15: Feedback when no content is found

Before discussing the article we are directed to, we will briefly see what happens if a word is not included in the dictionary (se Figure 15). The term Covid-19 taken from another article in the New York Times is a good illustration. After touching the screen, a page is visualized confirming the word consulted (at the top of the page), but informing us that no content has been found. Instead, it suggests two alternative actions: either to search on the Internet or to activate a different dictionary. The actions can be performed by simply touching the blue letters. This is an excellent example of good communication and the immediate feedback required by Norman (2013: 9) "where things go wrong", in this case due to a lemma lacuna. 


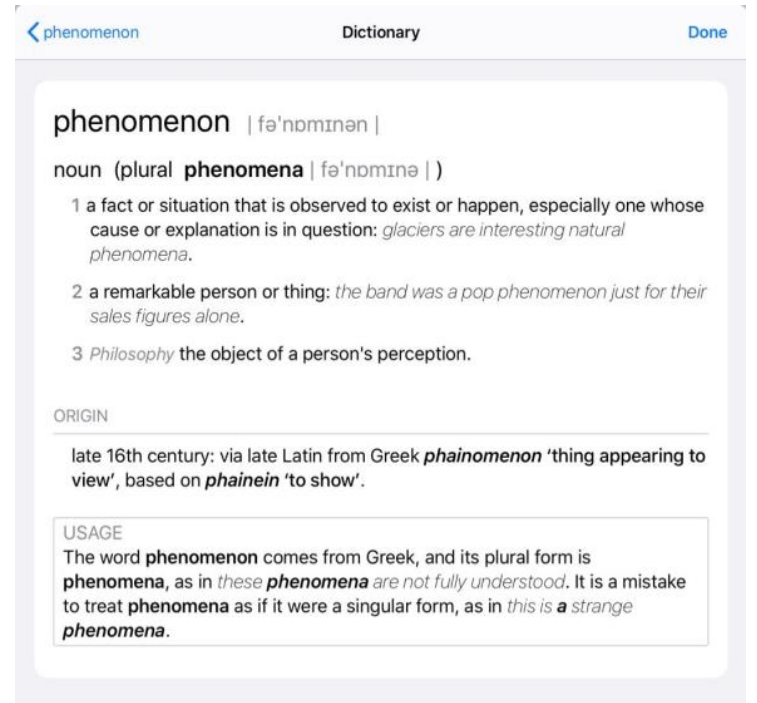

Figure 16: The article of phenomenon as presented in the iPad

Figure 16 shows the full article of phenomenon taken from the Oxford Dictionary of English. In terms of affordances and signifiers, the presentation appears perfect. If the users are happy with the information retrieved, they can easily end the consultation by clicking on "Done" in the upper right corner. And if they want to explore one of the other activated dictionaries and return to the previous page, they just need to click on the left-pointing arrow in the upper left corner. No special reference skills are needed so far.

However, in terms of "the needs that the design is intended to meet" (Norman 2013: 9), the article shown in Figure 16 is disappointing because the features do not match the requirements of the users. The designers seem to have forgotten that its genuine purpose is to assist the reading of a text. More than half of the lexicographical data included are superfluous in this respect. This applies to etymology, however interesting it is, as well as pronunciation (repeated twice) and usage as the consultation is not aimed at producing oral or written texts.

As Norman (2013: 24) comments, this kind of data overload can be "annoying", but it may also have more serious consequences. The treatment of phenomenon is relatively simple. But what about an orthographic word like water that belongs to two different word classes? If readers, for instance, touch the verb watering on the screen, they will be directed to an overview page where only the treatment of the noun is shown (Figure 17). This may create some confusion. Some users may try to activate other dictionaries (all of which are published by Oxford), but the result will be the same. Other users may immediately touch the arrow and go directly to the expanded article. However, here they will only find the various senses of the noun water on the default 
page, and they will have to scroll down to find the corresponding verb and the specific meaning they are looking for. Apart from being unnecessarily timeconsuming, this kind of structuring and relative data overload may, in the worst case, lead to an "obstructed" consultation that is "finally aborted with no result" (Gouws and Tarp 2017: 297)

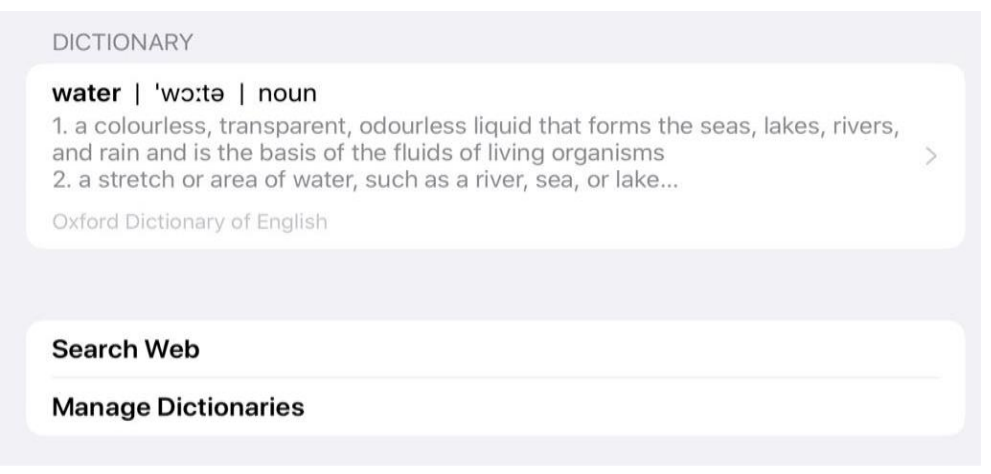

Figure 17: Dictionary overview: water

How can this sad ending to a happy journey be explained? We can only guess. It may result from a blurred definition of the users' real needs in a particular context (reading). The database sustaining the Oxford Dictionary of English may not, although it seems inconceivable, permit the extraction of the data categories required for the iPad. An explanation could also be that Apple, without having second thoughts, has just licensed this and other Oxford dictionaries due to their prestige and well-known quality. In any case, it is definitely a question of bad project management and lack of healthy interdisciplinary collaboration. It is a broad hint that lexicographers urgently need to dig in their own backyard, engage in interdisciplinary collaboration, and be better to "understand the viewpoint" of other experts and "think of the design from the viewpoint of the person" who is going to use it (Norman 2013: 35). The problem here is clearly not the users' reference skills but a design that is not sufficiently focused on their needs in a particular situation.

\section{Design of lexicography-assisted writing assistants}

Human-centered design must be understood in a broader perspective. Lexicography is no exception. Even if the target users' "needs, capabilities, and behavior" seem to have been properly accommodated in the design of a digital dictionary, there can be no absolute guarantee that they will pick up the right information in a concrete consultation. Some users may still erroneously feel that the information obtained meets their specific needs, and then be unaware of the difficulties they face when applying it in a concrete context. This is a well- 
known phenomenon which most teachers of non-native languages may have observed hundreds, if not thousands, of times. Learners who consult traditional dictionaries may, for instance, unintentionally have chosen the wrong equivalent among several possible candidates. This is one of the arguments in favor of teaching reference skills. But is this really the best solution? And does it work at all in these complex cases?

In the last instance, the underlying problem is, obviously, that the properties of the dictionary consulted do not sufficiently cater for the users' capabilities and behavior. From a narrow lexicographical perspective, a solution would be to introduce additional data into the dictionary, for instance, more explicit definitions of the respective senses and equivalents followed by a larger number of context examples. However, this would probably have negative collateral consequences such as data overload, more complex access routes, longer consultation time, bigger workload for the lexicographers, and higher production costs. So, what could the alternative be?

One option is to take a broader perspective on dictionary usage and perform a so-called root cause analysis. This implies that the overall activity is separated into goals and subgoals by persistently "asking 'Why?' until the ultimate, fundamental cause of the activity is reached" (Norman 2013: 42). Norman provides an example: Somebody buys a quarter-inch drill, not because they want a drill, but because they need a quarter-inch hole. However, "perhaps they don't really want the hole, either; they want to install their bookshelves" (p. 44). Hence, the hole is "an intermediate goal", whereas the real goal is to install shelves that can be used to store books. In this connection, he philosophizes:

Most innovation is done as an incremental enhancement of existing products. What about radical ideas, ones that introduce new product categories to the marketplace? These come about by reconsidering the goals, and always asking what the real goal is. (Norman 2013: 43)

In the above example, a reconsideration of the ultimate goal could lead to "methods that don't require holes", or e-books "that don't require bookshelves". The trick is "to develop observational skills" to detect these goals (p. 43).

Now, what is the ultimate goal of a dictionary consultation? Nesi (2015: 584) observes that people usually "are doing something else" when they resort to dictionaries. The function theory (Tarp 2008) that subdivides this "something else" into reading, writing, translating, and learning, among others, may assist us to further develop this idea. In the previous section, we discussed problems related to reading. Let us now take writing in a second language as an example.

The information retrieved from dictionary consultation during the L2writing process is not a goal in itself, it is a subgoal. To find the real goal, we first need to ask why the person writes the text, and then we should figure out what kind of text is required. Is it a job application, a love letter, a technical report, an academic article, or any other text genre? An application, for instance, usually serves the purpose of getting a job and earning some money 
that can sustain the family. Hence, the "ultimate, fundamental cause of the activity" is to sustain the family. Instead of offering an "enhanced dictionary" to assist the job application, a "radical idea" could, thus, be to "reconsider the goal" and pay the applicant's family some money. This may be a wise step in specific cases, but it goes far beyond the scope of lexicography. The ultimate lexicographically relevant goal appears to be the writing of an L2 text belonging to a specific genre.

A "radical idea" would then be to focus on this goal and develop a tool that offers more comprehensive writing assistance than traditional dictionaries. The tool should also be context-aware so its users are placed in a much more favorable situation when they have to decide which word to use in a concrete context. Tarp et al. (2017) have described such a tool (Write Assistant) that works integrated into the software people typically use when they write on laptops, smartphones, and tablets. Like other digital writing assistants, Write Assistant is driven by a language model that has been trained on a corpus applying statistic programming and increasingly also deep learning. This technology makes it possible - based upon the previously written text - to suggest the words most likely to be the next in a concrete context. Existing writing assistants with these characteristics are mostly monolingual, but the one mentioned is bilingual. It does not only allow non-native writers to type L2 words but also L1 words if they have doubt about the words that can be used to express a particular idea in L2. As illustrated in Figure 18, the tool will then automatically look up in a lexicographical database, pick up the L2 equivalents, and present them in a prioritized order with the most likely candidates listed first.

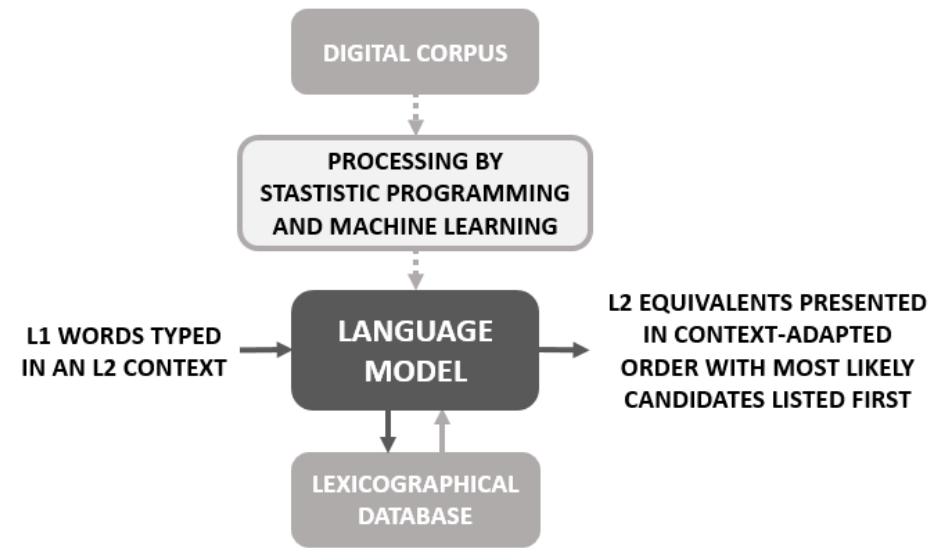

Figure 18: Schematic overview of an L2-writing assistant

Thus, a new principle has been added in the long-lasting lexicographical discussion of the most convenient ordering of senses and equivalents, namely the 
principle of automatic, context-aware ordering that is unique to each consultation (see A and B in Figure 19).

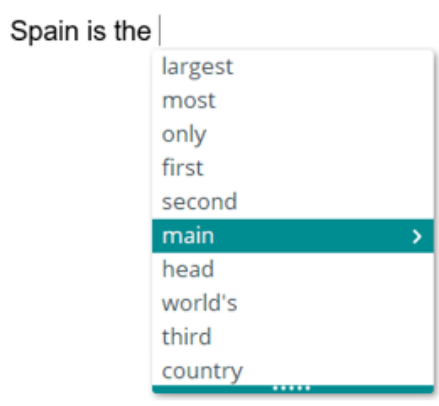

A

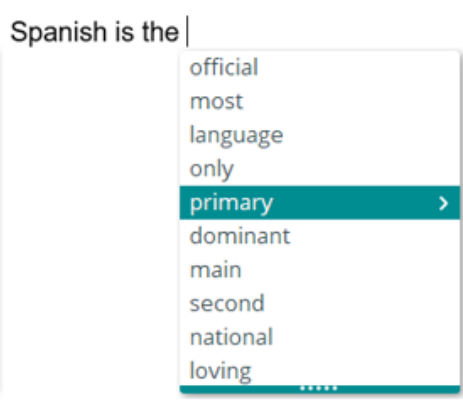

B

Spanish is the lengual
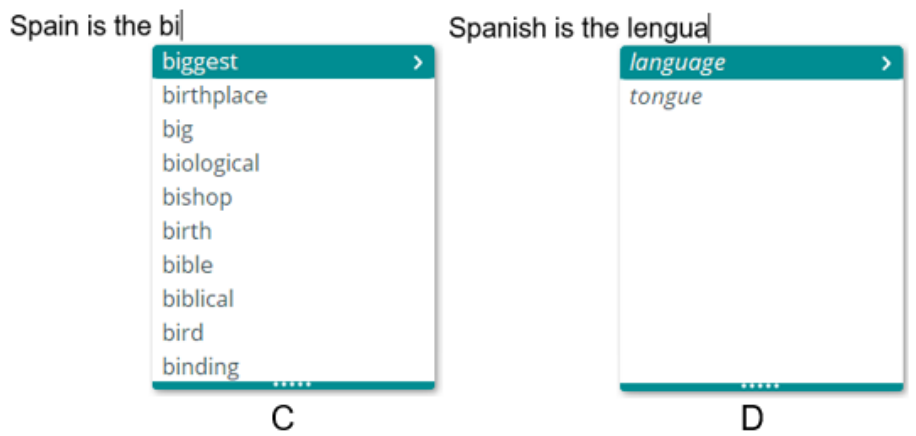

Figure 19: Some functionalities. A \& B: context-adapted suggestions; C: likely word terminations; D: L2 equivalents (in italics)

As mentioned above, learners are often unaware of the mistakes they make when using equivalents in a concrete context. L2-writing assistants like the one described have the potential to considerably reduce this risk. If learners have doubts about the meaning of any of the suggested L2 words, they can activate the integrated dictionary by a simple click or touch on the screen, that is, without leaving the document they are working on. Although the technology can still be improved, the design with its affordances and signifiers is, up to this point, generally convincing from a human-centered perspective (see Figure 19). The suggestions for word terminations, next-words, and equivalents are automatically generated by the tool and presented to the users in an aesthetic design when the latter start typing. The green bar indicates how to navigate between the respective suggestions, and the small right-pointing arrow invites the users to start a lexicographical consultation. So far so good. Now the trouble starts. The users who continue to the integrated dictionary will experience something similar to what happened on the iPad. 


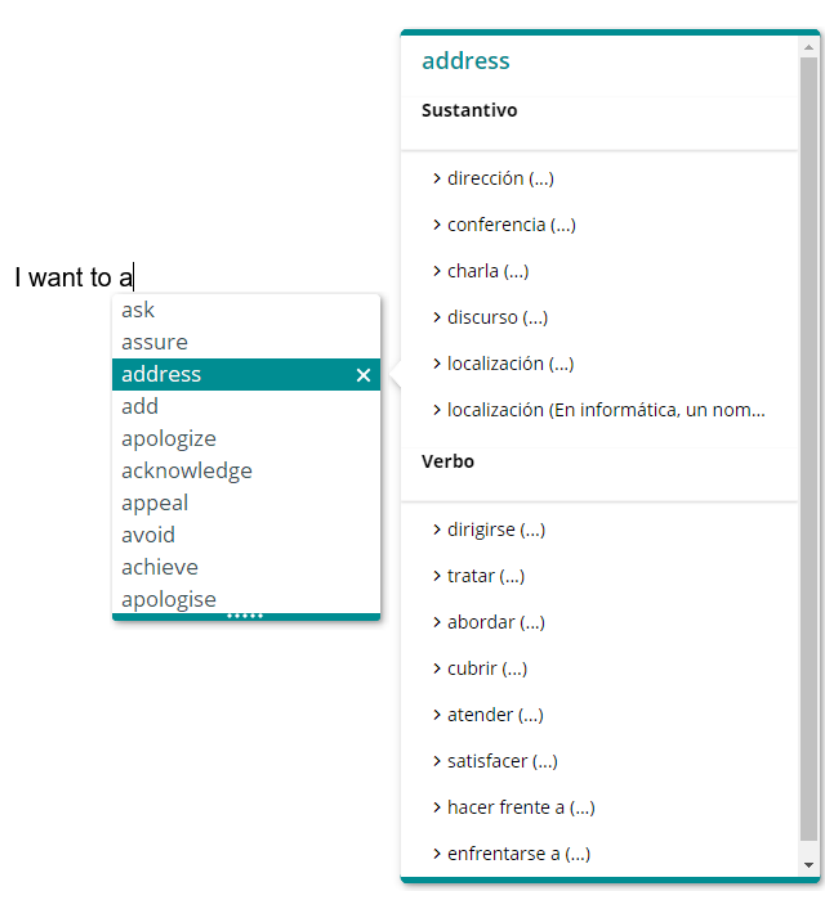

Figure 20: Consultation of address: default page

The overall design is still aesthetic and functional with the use of pertinent signifiers like the sign "..." and right-pointing arrows signaling how to proceed (see Figure 20). A slightly darkened background indicates when an item is open and a down-pointing, green arrow shows how to close it again (see Figure 21). Feedback is given when there is a lemma lacuna. Yet, the lack of relevant lexicographical data is obvious. The users' needs in terms of L2 writing are clearly much more complex than the ones related to L1-text understanding discussed in the previous section. Various types of lexicographical data are required to give maximum assistance to non-native learners: part of speech, inflection, L1 definitions of L2 words, equivalents, cultural and pragmatic notes, synonyms and antonyms, syntactic properties, collocations, and example sentences, among others. Most of these central data types are completely missing. The only data provided to the users are part of speech, equivalents, and example sentences. This is clearly not enough. Cumulative equivalents, for instance, are helpful to text understanding, but insufficient to L2 writing as many of them are polysemous and it is difficult for users to figure out which of the senses correspond to the meaning they want to express. Besides, they will not be less confused by the fact that all example sentences addressed to the eight verb senses in Figure 21 are identical, except for the first one (dirigirse). Regretfully, this is no exception to the rule. 


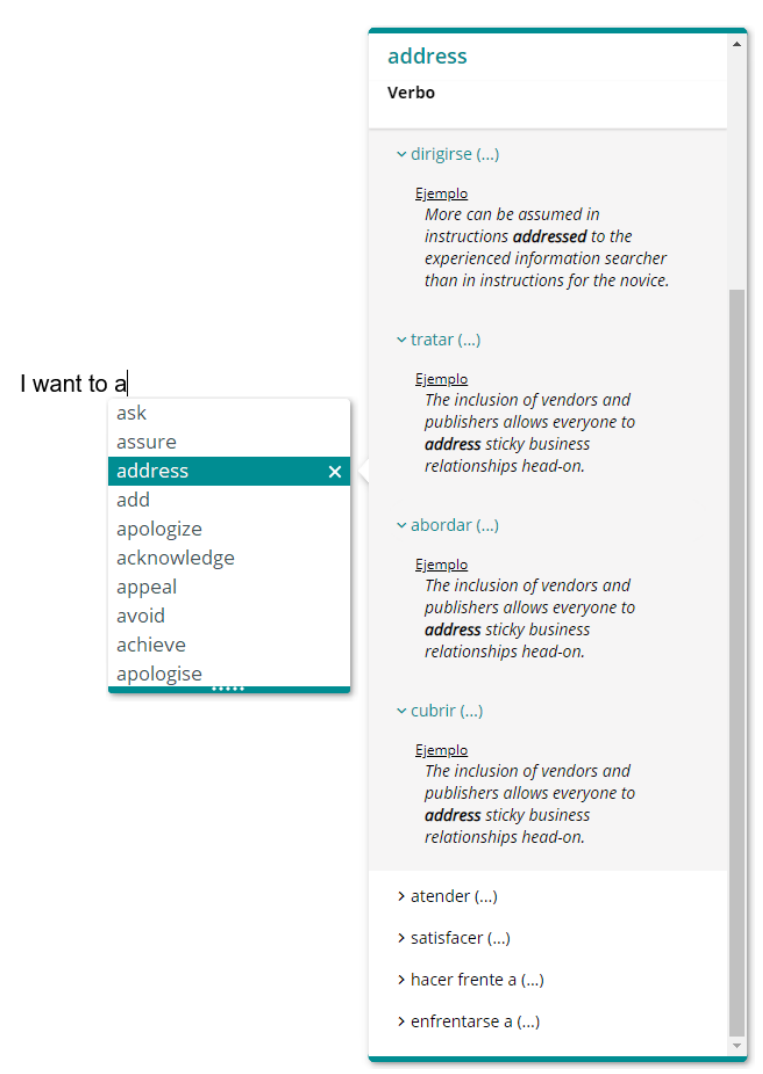

Figure 21: Consultation of address with four expanded verb senses

According to Fuertes-Olivera and Tarp (2020), who have analyzed the lexicographical assistance offered by Write Assistant, the problems begin in the existing lexicographical databases:

These databases were originally compiled to sustain printed or digital dictionaries. The experience so far indicates that they are less suited to feed a tool like Write Assistant. They may not contain the required data types. They may not have them in the necessary quantity, or they have stored them in such a way that they cannot be used properly. In any case, it seems necessary to restart almost from scratch.

The two authors have come up with an alternative proposal based upon the biscopal English-Spanish Valladolid-UVa Database (under construction); see Fuertes-Olivera et al. (2018). The proposal aims at avoiding frustrating phenomena such as long access routes, data overload, scrolling down, and incomprehensible metatexts, all of which may lead to mistakes and abortive consultations. It is being gradually incorporated into Write Assistant pari passu with 
the expansion of the database. The new articles do have definitions. But it takes time to complete such work.

We started this section stressing that "there can be no absolute guarantee" that users will retrieve "the right information in a concrete consultation". This is true in the sense that writers always have the sole responsibility for the final text. Irresponsible behavior may still lead to mistakes. But writing assistants can go a long way to reduce the risk. The technology has far from exhausted its potential. The enhanced application of artificial intelligence, for instance, will beyond any doubt make allowance for improved collocational, syntactic, stylistic, and genre-adapted assistance (see Tarp 2020). The service can be proactive and even furnished in the form of alerts. In this way, writing assistants with human-centered design can accommodate their users' "capabilities and behavior". The Achilles heel is the lexicographical component that, so far, takes insufficient account of the users' needs in connection with L2 writing. Hence, we can conclude that the fundamental problem is not the users' reference skills but the lexicographers' ability to determine and produce the data required to meet the latter's needs.

Cutting-edge technology does not make lexicography obsolete. But it implies interdisciplinary collaboration as well as a qualitative shift from the traditional stand-alone dictionary to an integrated lexicographical product that is context-aware and user-centered.

\section{Towards a new lexicographical culture}

The notion of reference skills must be seen from a historical perspective. Hausmann (1989: 13) observes that the history of lexicography shows a strained relationship between the discipline and society. According to him, the terms dictionary culture and user-friendliness are used to describe this friction. Userfriendliness implies that lexicography adapts to society whereas dictionary culture means that society adapts to lexicography. User-friendliness prevails when dictionaries are made from which the intended target users can retrieve the kind of lexicographical information they require. By contrast, a dictionary culture prevails when lexicographers know the target users have acquired the necessary reference skills to successfully consult their dictionaries. The conflict described by Hausmann implies a complementary relation where users have to complement the efforts of the lexicographers to ensure successful dictionary usage. The lexicographers make the dictionaries, and the users have the responsibility to enable themselves to find and retrieve the required information from the condensed and often strongly codified items as the ones we saw in the dictionary from the Royal Spanish Academy (Figure 6).

The discussion has divided the waters between lexicographers in favor of one approach or the other. Gouws (2016), for instance, defends a so-called "comprehensive dictionary culture" that includes both the traditional concept of dictionary culture and that of user-friendliness. At the other extreme, we 
have lexicographers like Yamada (2014) who still promotes the teaching of reference skills. In a review of Yamada's Oxford Guide to the practical usage of English monolingual learners' dictionaries, Rundell (2015b: 27) writes:

\begin{abstract}
Yamada believes that, when a user's search for information is unsuccessful, "either the dictionary or the user is to blame". My default position is that if users can't readily find what they are looking for, the fault lies squarely with the dictionary. ... Few students will be fortunate enough to have a teacher who understands dictionaries as well as the author of the guide. In most cases, they must rely on their dictionary being well enough designed to make its use intuitive.
\end{abstract}

We fully agree with Rundell, especially when he stresses that users should be able to use dictionaries intuitively. The concept of intuitive use is even more advanced than that of traditional user-friendliness. It may just have been a dream a few decades ago, but it is now achievable due to new technologies. We refer to a practice with this user perspective as a new lexicographical culture as the discipline is no longer concerned only with dictionaries, but also with other types of information tools. In this culture, it is the lexicographers' sole responsibility that their products can be used successfully by the target group. No special reference skills are required. Of course, users should have some basic capabilities. They should be able to read and write. They should have a certain proficiency level in at least one relevant language. And for some products like specialized subject-field dictionaries, they should also have some basic knowledge of the discipline in question. But in terms of using the device, and navigating in it, no special skills should be required. The design should be humancentered, or user-centered, in full compliance with the principles outlined by Norman (2013) and discussed in the previous sections.

The new culture places more responsibility on the shoulders of lexicographers in terms of needs detection as well as data preparation and presentation. They should refine their observational skills to detect real user needs, as users themselves may not be aware of these needs. The initial observation should, therefore, not be performed when users are using lexicographical devices, but in the situations prior to the consultation process when the needs occur. The lexicographical data that can meet these needs should then be prepared meticulously and stored in well-designed databases that contain as much relevant data as possible. The lexicographical data are the central issue and should be high-quality. This implies, apart from giving response to the detected user needs, that definitions and metatexts are easily understandable and written in a plain, user-oriented language.

Finally, the data should be presented to the users in a way that guarantees intuitive use and smooth consultation by means of appropriate techniques. This requires test-driven development and elegant use of affordances and signifiers. Users should be able to find what they need in as few clicks as possible. Scrolling down should be reduced to a minimum and should not be employed as a means to limit the number of clicks. No relevant navigation routes should 
be blocked. Blind alleys and no-return situations like the ones we saw in Lexico and Cambridge should be banned. Users should be allowed to close expanded texts and pop-up windows, return to the previous page, and jump to the top after scrolling down. Data overload with overcrowded pages that may divert the users' attention and create anxiety should be avoided. Any item, data, symbol, line, or button that cannot be justified from a user perspective should be eliminated.

To achieve all this, a strong engagement with experts from other fields is required, among them information engineers, programmers, industrial designers, and professional testers. Hopefully, this will increasingly become the new lexicographical normality.

\section{Acknowledgement}

This work is based on the research supported in part by the National Research Foundation of South Africa (Grant specific unique reference number (UID) 85434). The Grantholder acknowledges that opinions, findings and conclusions or recommendations expressed in any publication generated by the NRF supported research are that of the author(s), and that the NRF accepts no liability whatsoever in this regard.

\section{Bibliography}

\section{A. Online dictionaries}

Cambridge Dictionary. https://dictionary.cambridge.org/

Diccionario de la Lengua Española. https://dle.rae.es/

Longman Dictionary of Contemporary English Online. https://www.ldoceonline.com/

Macmillan Dictionary. http://www.macmillandictionaries.com/

Merriam-Webster Dictionary. https://www.merriam-webster.com/

Ordbogen.com. https://www.ordbogen.com/

Oxford Dictionary on Lexico. https://www.lexico.com/

\section{B. Other literature}

Bergenholtz, H. and S. Tarp. 2003. Two Opposing Theories: On H.E. Wiegand's Recent Discovery of Lexicographic Functions. Hermes, Journal of Linguistics 31: 171-196.

Fuertes-Olivera, P.A. and S. Tarp. 2020. A Window to the Future: Proposal for a Lexicographyassisted Writing Assistant. Lexicographica 36: 257-286.

Fuertes-Olivera, P.A., S. Tarp and P. Sepstrup. 2018. New Insights in the Design and Compilation of Digital Bilingual Lexicographical Products: The Case of the Diccionarios Valladolid-UVa. Lexikos 28: 152-176. 
Gouws, R.H. 2016. Increasing the Scope of the Treatment of Specialised Language Terms in General Dictionaries. Schierholz, S., R.H. Gouws, Z. Hollós and W. Wolski (Eds.). 2016. Wörterbuchforschung und Lexikographie: 101-118. Berlin: De Gruyter.

Gouws, R.H. and S. Tarp. 2017. Information Overload and Data Overload in Lexicography. International Journal of Lexicography 30(4): 389-415.

Hanks, P. 2013. Lexicography from Earliest Times to the Present. Allan, K. (Ed.). 2013. The Oxford Handbook of the History of Linguistics: 503-536. Oxford: Oxford University Press.

Hartmann, R.K.K. 1989. Sociology of the Dictionary User: Hypothesis and Empirical Studies. Hausmann et al. (Eds.). 1989: 102-111.

Hausmann, F.J. 1989: Die gesellschaftlichen Aufgaben der Lexikographie in Geschichte und Gegenwart. Hausmann et al. (Eds.). 1989: 1-19.

Hausmann, F.J., O. Reichmann, H.E. Wiegand and L. Zgusta (Eds.). 1989. Wörterbücher, Dictionaries, Dictionnaires. An International Encyclopedia of Lexicography. Volume 1. Berlin/New York: Walter de Gruyter.

Kirkpatrick, B. 1989. User's Guides in Dictionaries. Hausmann et al. (Eds.). 1989: 754-761.

Nesi, H. 2015. The Demands of Users and the Publishing World: Printed or Online, Free or Paid for? Durkin, P. (Ed.). 2015. The Oxford Handbook of Lexicography: 579-589. Oxford: Oxford University Press.

Nielsen, S. 2005. User's Guides. Barz, I., H. Bergenholtz and J. Korhonen (Eds.). 2005. Schreiben, Verstehen, Übersetzen, Lernen. Zu ein- und zweisprachigen Wörterbüchern mit Deutsch: 137-146. Frankfurt am Main: Peter Lang.

Norman, D. 2004. Emotional Design: Why We Love (or Hate) Everyday Things. New York: Basic Books.

Norman, D. 2010. Living with Complexity. Cambridge: MIT Press.

Norman, D. 2013. The Design of Everyday Things. New York: Basic Books.

Rundell, M. 2015a. From Print to Digital: Implications for Dictionary Policy and Lexicographic Conventions. Lexikos 25: 301-322.

Rundell, M. 2015b. Review Article: Shigeru Yamada. Oxford Guide to the Practical Usage of English Monolingual Learners' Dictionaries: Effective Ways of Teaching Dictionary Use in the English Class. Kernerman Dictionary News 23: 26-27.

Tarp, S. 2008. Lexicography in the Borderland between Knowledge and Non-knowledge. General Lexicographical Theory with Particular Focus on Learner's Lexicography. Tübingen. Max Niemeyer.

Tarp, S. 2020. Integrated Writing Assistants and their Possible Consequences for Foreign-Language Writing and Learning. Bocanegra-Valle, A. (Ed.). 2020. Applied Linguistics and Knowledge Transfer: Employability, Internationalization and Social Challenges: 53-76. Bern: Peter Lang.

Tarp, S., K. Fisker and P. Sepstrup. 2017. L2 Writing Assistants and Context-Aware Dictionaries: New Challenges to Lexicography. Lexikos 27: 494-521.

Vrbinc, M. and A. Vrbinc. 2020. User Guides in Monolingual Slovenian Dictionaries: Users' Perspective. Lexicography 7(1-2): 123-134.

Wiegand, H.E. 1977. Nachdenken über Wörterbücher. Aktuelle Probleme. Drosdowski, G., H. Henne and H.E. Wiegand (Eds.). 1977. Nachdenken über Wörterbücher: 51-102. Mannheim/Vienna/ Zürich: Bibliographisches Institut.

Wiegand, H.E. 1990. Printed Dictionaries and their Parts as Texts. An Overview of More Recent Research as an Introduction. Lexicographica 6: 1-126. 
Wiegand, H.E. 1998. Wörterbuchforschung. Untersuchungen zur Wörterbuchbenutzung, zur Theorie, Geschichte, Kritik und Automatisierung der Lexikographie. Volume 1. Berlin/New York: Walter de Gruyter.

Wiegand, H.E., S. Beer and R.H. Gouws. 2013. Textual Structures in Printed Dictionaries: An Overview. Gouws, R.H., U. Heid, W. Schweickard and H.E. Wiegand (Eds.). 2013. Dictionaries. An International Encyclopedia of Lexicography. Supplementary Volume: Recent Developments with Focus on Electronic and Computational Lexicography. Handbücher zur Sprach- und Kommunikationswissenschaft 5.4: 31-73. Berlin/Boston: Mouton de Gruyter.

Yamada, S. 2014. Oxford Guide to the Practical Usage of English Monolingual Learners' Dictionaries: Effective Ways of Teaching Dictionary Use in the English Class. Tokyo: Oxford University Press. 